\title{
Damping of Selective-Laser-Melted NiTi for Medical Implants
}

\author{
Michael de Wild, Fabian Meier, Therese Bormann, Chaim B.C. Howald, and Bert Müller
}

(Submitted September 30, 2013; published online February 7, 2014)

\begin{abstract}
NiTi exhibits distinct damping properties associated with the martensite-austenite transformation. We fabricated net-shape NiTi parts layer-by-layer using a laser beam that locally melted the NiTi powder. The damping properties of such NiTi parts were analyzed by the decay of cantilever vibrations in comparison to conventionally prepared NiTi. The dynamic modulus as a function of the temperature was derived from the resonant frequency. We found that the two cantilevers showed a damping ratio of about 0.03 at temperatures below austenite start, maximal values of up to 0.04 in the transformation regions and low values of about 0.005 above austenite finish. The results indicate that selective-laser-melted NiTi qualifies for the fabrication of shock-absorbing medical implants in the same manner than conventionally produced NiTi.
\end{abstract}

Keywords damping, nondestructive testing, NiTi, powder metallurgy, selective laser melting

\section{Introduction}

Owing to biocompatibility, mechanical strength, and the pseudoelastic and pseudoplastic effects (Ref 1,2), the shape memory alloy NiTi is often used for medical implants. The diffusion-less, solid-solid, first-order phase transformation between the low-temperature martensitic (monoclinic, B19') and the high-temperature austenite phase (cubic, B2) does not only explain the phenomena pseudoelasticity, pseudoplasticity, and two-way shape memory effect but also the distinct damping and shock absorption behavior. For a variety of applications, the mechanical damping capacity and shock absorbance of NiTi are of particular interest: spinal and dental implants, bulletproof vests, dampers in automotive, and sports applications (Ref 2).

Selective laser melting (SLM) is more flexible than conventional fabrication routes and allows for net-shape fabrication of rather complex microstructures. Therefore, it is a promising technique to prepare medical implants or parts of them. For SLM fabrication, CAD-designed structures are layer-by-layer

This article is an invited paper selected from presentations at the International Conference on Shape Memory and Superelastic Technologies 2013, held May 20-24, 2013, in Prague, Czech Republic, and has been expanded from the original presentation.

Michael de Wild, Fabian Meier and Chaim B.C. Howald, Institute for Medical and Analytical Technologies, University of Applied Sciences Northwestern Switzerland, 4132 Muttenz, Switzerland Therese Bormann, Institute for Medical and Analytical Technologies, University of Applied Sciences Northwestern Switzerland, 4132 Muttenz, Switzerland; and Biomaterials Science Center, University of Basel, c/o University Hospital, 4031 Basel, Switzerland; and Bert Müller, Biomaterials Science Center, University of Basel, c/o University Hospital, 4031 Basel, Switzerland. Contact e-mail: michael.dewild@fhnw.ch. fabricated by means of a laser that locally melts the scanned powder. The additive manufactured, solid NiTi material is created by welding together micrometer-sized prealloyed NiTi particles, which leads to an anisotropic microstructure with elongated grains (Ref 3, 4). In contrast, conventionally produced NiTi material exhibits a more regular microstructure with globular grains (Ref 5). It was shown that in spite of its specific microstructure, SLM-fabricated NiTi parts undergo phase transformation similar to conventional NiTi material (Ref 6, 7). In particular, the SLM NiTi also shows pseudoplastic (Ref 8, 9) and pseudoelastic mechanical properties (Ref 4, 10). However, there is no study reported on the damping properties of SLM NiTi. We hypothesize that the damping properties of SLM NiTi correspond to the ones of conventionally produced parts, although the local re-melting by the laser beam gives rise to a characteristic microstructure and an enhanced level of defect-mediated stress and strain.

\section{Materials and Methods}

\subsection{Specimen Preparation}

Two types of NiTi cantilevers with a dimension of $50 \times 10 \times 1 \mathrm{~mm}^{3}$ were prepared. One type, termed as conventional NiTi, was made from conventional, cold worked NiTi (55.92 wt.\% Ni, Memry GmbH, Weil am Rhein, Germany). The second type, termed as SLM NiTi, was built by means of the SLM-Realizer100 (SLM-Solutions, Lübeck, Germany) taking advantage of a $100 \mathrm{~W}$ fiber laser (Ref 4). The SLM $\mathrm{NiTi}$ is based on pre-alloyed powder (starting material 55.96 wt. $\%$ Ni). The particle size distribution of the powder showed a $d_{50}$ value of $57 \pm 1 \mu \mathrm{m}$ measured with laser diffraction (Helos, with dry disperser RODOS and vibratory feeder, Sympatec GmbH, Clausthal-Zellerfeld, Germany), and the particles display a spherical shape, cp. Fig. 1. The cantilevers were annealed at a temperature of $500^{\circ} \mathrm{C}$ for a period of $25 \mathrm{~min}$ in $\mathrm{Ar}$ atmosphere (high-temperature furnace, Nabertherm N11, Nabertherm GmbH, Bremen, Germany) followed by air cooling in order to shift the austenite start 

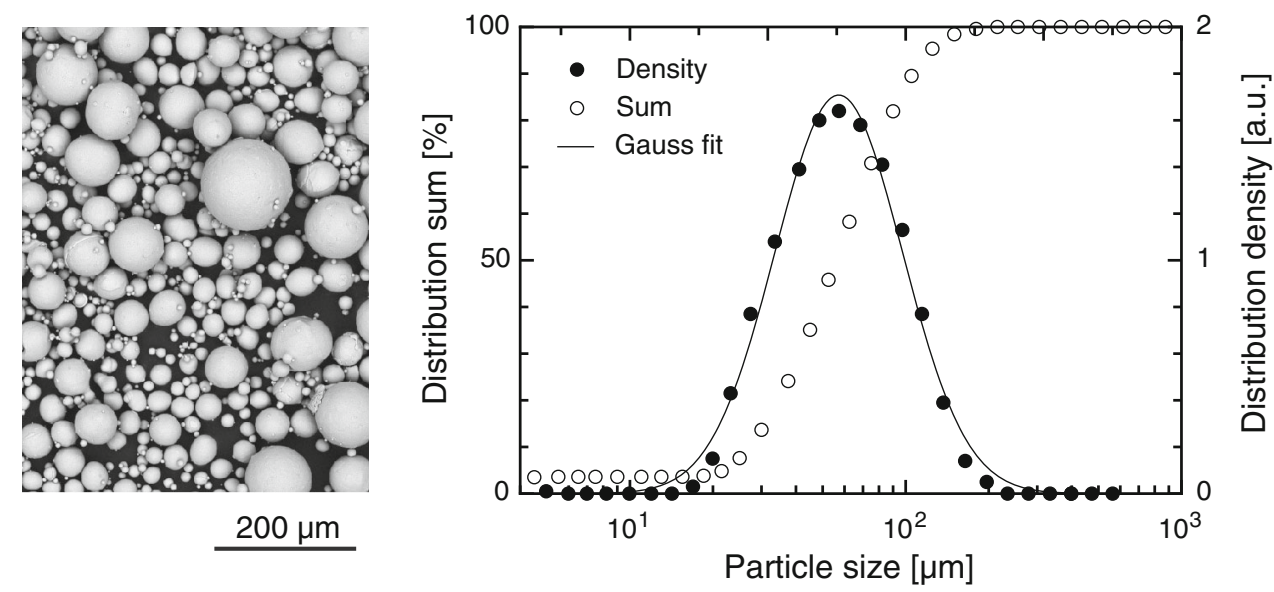

Fig. 1 SEM image and particle size distribution of the pre-alloyed starting NiTi powder for SLM fabrication of the cantilevers

temperature $\mathrm{A}_{\mathrm{s}}$ above $0^{\circ} \mathrm{C}$. The phase transition temperatures were determined by means of differential scanning calorimetry (DSC30, TA-Controller TC 11, Mettler-Toledo GmbH, Greifensee, Switzerland) in the temperature range between -125 and $100^{\circ} \mathrm{C}$ with heating/cooling rates of $10 \mathrm{~K} / \mathrm{min}$.

A titanium reference (Goodfellow, Cambridge, UK, 99.6\% Ti, annealed) was included into the study.

\subsection{Damping Analysis}

The cantilevers placed in a climate chamber to guarantee well-defined temperatures were fixed on one end. A thermocouple (Type J, Fe-CuNi) directly attached to the NiTi cantilever with heat-conductive paste (CoolerMaster ${ }^{\circledR}$ HTK002, Conrad, Dietikon, Switzerland) and read out with a digital multimeter (U1253B, Agilent Technologies Schweiz, Basel, Switzerland) served for temperature measurement and control. The measurements included 16 pre-defined temperature ranges during continuous heating from -20 to $50^{\circ} \mathrm{C}$ with heating/ cooling rates of 1.0-1.5 K/min. After excitation by $1.5-3.0 \mathrm{~mm}$ elongation, the decay of the amplitude was acquired during a period of $0.4 \mathrm{~s}$ tracking the sinusoidal motion $x(t)$ of the free cantilever end with a high-speed camera (MotionPro Y3 S2 Mono, $8 \mathrm{kHz}, 288 \times 192$ pixels, Videal AG, Niederoenz, Switzerland) and the Motion Studio ${ }^{\mathrm{TM}}$ controlling software (Version 2.10.05, 32 Bit, IDT Inc., Tallahasse, USA). The obtained sequences were analyzed offline with the ProAnalyst ${ }^{\circledR}$ software (Professional edition, Xcitex Inc., Cambridge, Massachusetts, USA) by means of the tracking the marker positioned at length $L$. The temporal path of the marker is well described as damped harmonic oscillation:

$x(t)=A \exp (-\alpha t) \cos (2 \pi t f+\varphi)+c$.

The decay parameter $\alpha$ quantifies the exponential decay of the oscillation with the frequency $f$. The related damping ratio $\zeta=$ $\alpha / 2 \pi f$ was determined performing fits with the software OriginPro ${ }^{\mathrm{TM}}$ (Version 8.6.0G 64-bit Sr3 b99, OriginLab Corporation, Northampton, USA). In order to uncover the eigenmodes and the related eigenfrequencies, we applied the software $\mathrm{Comsol}^{\mathrm{TM}}$ V.4.3 (Comsol Multiphysics, Stockholm, Sweden).

\subsection{Elastic Modulus Determination}

After cooling the specimens to liquid nitrogen temperature, which ensured the complete martensitic transformation, the
Young's modulus $E$ was derived from tensile measurements with the uniaxial testing machine (Z100 THW allround-line, X-force load cell, Zwick GmbH \& Co. KG, Ulm, Germany). The martensitic phase was characterized $10 \mathrm{~K}$ below the austenite start temperature $A_{\mathrm{s}}$. For the austenite phase, we have chosen conditions $10 \mathrm{~K}$ above the austenite finish temperature $A_{\mathrm{f}}$. A laser extensometer (LaserXtense) with high-definition camera allowed for the determination of strain.

Additionally, the dynamic modulus $E_{\mathrm{d}}$ of the excited cantilevers (free vibrations) was approximated by means of

$E_{\mathrm{d}}=\rho\left(\frac{f_{n} L^{2}}{\alpha_{n} \pi K}\right)^{2}$

with eigenfrequency $f_{n}$, cantilever length $L$, constant $\alpha_{n}$ for fundamental oscillation mode, density $\rho$, constant $K=d / \sqrt{ } 12$ for rectangular cantilevers with thickness $d$ (Ref 11).

\section{Results}

\subsection{Determination of the Transition Temperatures}

The DSC curves of SLM and conventional NiTi are shown in Fig. 2. Both curves express a phase transformation and have pronounced austenite (reverse transformation), martensite, and R-phase peaks (forward transformation), which are in a similar temperature range, see Table 1 . The Ti reference, as expected, does not show any exotherm or endotherm signs because at the applied temperatures (and up to $882^{\circ} \mathrm{C}$ ), it appears in the hexagonal $\alpha$-phase.

\subsection{Damping Measurements}

The calculated eigenmodes and eigenfrequencies are listed in Table 2. The estimated eigenfrequency of the prominent fundamental mode was $334 \mathrm{~Hz}$ assuming an elastic modulus $E=50 \mathrm{GPa}$ and a density of $\rho=6450 \mathrm{~kg} / \mathrm{m}^{3}$. All modes of higher orders are separated by at least $1.57 \mathrm{kHz}$.

Once the oscillatory movement of the excited cantilever was tracked, the trajectory of the damped harmonic oscillation was evaluated as represented in Fig. 3a. The experimental data were fitted with $\mathrm{Eq} 1$. In the example shown in Fig. 3 for the conventional NiTi at the temperature of $10^{\circ} \mathrm{C}$, the following fit parameters were derived: frequency $f=(291.6 \pm 0.4) \mathrm{Hz}$, 


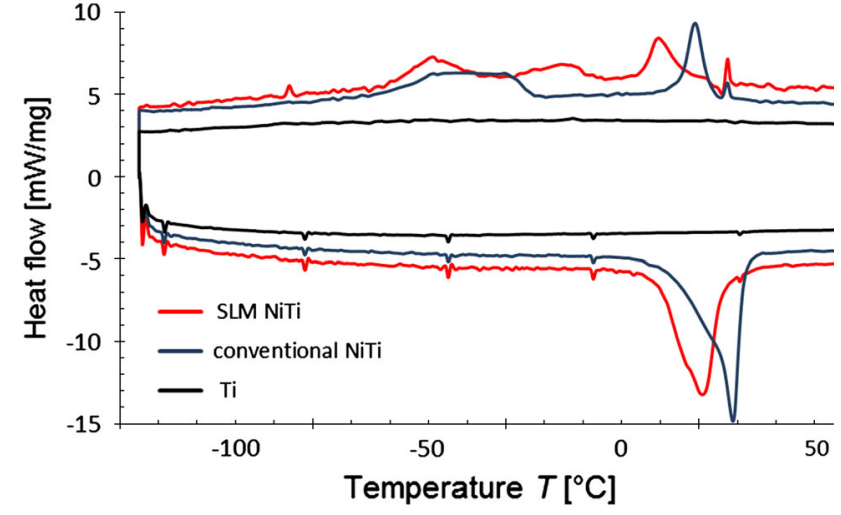

Fig. 2 Experimental DSC curves of conventional NiTi, SLM NiTi, and titanium with artifacts at switchover points (Color figure online)

Table 1 Experimental phase transformation temperatures, i.e., austenite start $A_{\mathrm{s}}$, austenite peak $A_{\mathrm{p}}$, martensite peak $M_{\mathrm{p}}$, and $R$-phase peak $R_{\mathrm{p}}$, of annealed conventional and SLM materials

\begin{tabular}{lcr}
\hline & Conventional NiTi & SLM NiTi \\
\hline$A_{\mathrm{s}},{ }^{\circ} \mathrm{C}$ & $10 \pm 1$ & $8 \pm 1$ \\
$A_{\mathrm{p}},{ }^{\circ} \mathrm{C}$ & $29 \pm 1$ & $21 \pm 1$ \\
$M_{\mathrm{p}},{ }^{\circ} \mathrm{C}$ & $-30 \pm 2$ & $-49 \pm 1$ \\
$R_{\mathrm{p}},{ }^{\circ} \mathrm{C}$ & $19 \pm 1$ & $10 \pm 1$ \\
\hline
\end{tabular}

Table 2 Modal analysis of the NiTi cantilever

\begin{tabular}{lccc}
\hline Mode & Order $\boldsymbol{i}$ & Frequency $\boldsymbol{f}, \mathbf{H z}$ & $\boldsymbol{f}_{\boldsymbol{i}} / \boldsymbol{f}_{\boldsymbol{I}}$ \\
\hline Fundamental vertical bending & 1 & 334 & 1.0 \\
Torsional twisting & 2 & 1910 & 5.7 \\
Higher order vertical bending & 3 & 2128 & 6.3 \\
Higher order twisting & 4 & 3295 & 9.8 \\
\hline
\end{tabular}

decay parameter $\alpha=(53.3 \pm 2.3) \mathrm{s}^{-1}$, amplitude $A=$ $(4.9 \pm 2.0) \mathrm{mm}$, offset $c=(0.055 \pm 0.004) \mathrm{mm}$, and phase shift $\varphi=-(42.3 \pm 0.4)$ degrees. The transfer function of the measured data with a clear resonance peak at the frequency of $289 \mathrm{~Hz}$ is depicted in Fig. 3b. It becomes obvious that the motion of the bar in the observed temperature range is a single sinusoidal mode with a frequency of about $300 \mathrm{~Hz}$. No nonlinear distortion and no mode of higher order were detected, cp. Table 2. The damping ratios of SLM and conventional NiTi as a function of the temperature are summarized in Fig. 4b.

The damping is phase dependent. In accordance to (Ref 12), the determined damping ratio $\zeta$ is maximized in the range of the phase transformations from martensite to austenite (SLM NiTi: $0.041 \pm 0.004$, conventional NiTi: $0.038 \pm 0.004$ ), from austenite to R-phase (conventional NiTi: $0.041 \pm 0.004$ ), and from R-phase to martensite (conventional NiTi: $0.038 \pm 0.004$ ). It corresponds to medium values for the martensite (SLM NiTi: $0.034 \pm 0.004$, conventional NiTi: $0.027 \pm 0.004)$ and the R-phase (conventional NiTi: $0.028 \pm 0.004)$, experiments during cooling not shown. Lowest values are found for the austenite (SLM NiTi: $0.003 \pm 0.004$, conventional NiTi: $0.002 \pm 0.004$ ).
Hence, no significant difference between the SLM and conventional NiTi is observed in the martensite and austenite phases.

For SLM NiTi, the increase in the damping ratio starts at a temperature of about $5^{\circ} \mathrm{C}$ and reaches its maximum at a temperature of about $10^{\circ} \mathrm{C}$. For the conventional NiTi, the increase of the damping ratio is first observed at a temperature of about $18^{\circ} \mathrm{C}$, which corresponds to the maximum of the damping ratio.

As expected, the damping ratio $\zeta$ of Ti reference in its stable $\alpha$-phase shows a constant value of $0.0075 \pm 0.0012$ throughout the complete temperature range.

\subsection{Determination of the Dynamic Modulus}

The dynamic modulus $E_{\mathrm{d}}$ of SLM and conventional NiTi as a function of the temperature, derived from the resonant frequency by Eq 2 with cantilever length $L=40 \mathrm{~mm}$, constant for fundamental oscillation mode $\alpha=0.1782$, density $\rho(\mathrm{Ni}-$ Ti) $=6450 \mathrm{~kg} / \mathrm{m}^{3}$, thickness of cantilevers $d=1 \mathrm{~mm}$, is shown in Fig. 4c. Again, three distinct regions were identified for SLM and conventional NiTi. As expected, the martensite state at relatively low temperature, i.e., well below the austenite start temperature $A_{\mathrm{s}}$ is characterized by a low modulus, the austenite phase at elevated temperatures $\left(T>A_{\mathrm{f}}\right)$ is much stiffer. The values differ from uniaxial testing, see Table 3 . The dynamic modulus of titanium gradually decreases with the temperature as usual.

\section{Discussion}

There are several methods to determine the damping ratio of natural and technical materials (Ref 14). The technique of inverted torsion pendulum is a suitable method to study the damping in the frequency range of $10^{-3}-200 \mathrm{~Hz}$ and temperature range of 4-600 K but is restricted to wires (Ref 15). Liu et al. (Ref 16) used dynamic mechanical tests at resonant frequency as a function of the temperature and tensioncompression cyclic loading at room-temperature to investigate the damping properties of conventional NiTi. The elastic and acoustic damping properties of NiTi single crystals were investigated with the ultrasound pulse echo method (Ref 17). The methods of resonant bar (Ref 12) and resonant string (Ref 18, 19) were applied to derive the temperature-dependent damping capacity. In this study, the damping properties of NiTi bars were analyzed by the decay of free vibrations as a function of the temperature. The flexural oscillations of the cantilever induce cyclic loading with alternating stress directions. During cyclic bending, different damping mechanisms can occur depending on the temperature ( $\operatorname{Ref} 12,20)$. In the heterogeneous lattices of martensite below the austenite starting temperature and in the R-phase, mechanical stress leads to the creation and movement of twin boundaries between the variants and thus to energy dissipation, i.e., to large damping characteristics. In the homogeneous cubic austenite lattice, i.e., above austenite finish temperature $A_{\mathrm{f}}$, no twin boundaries exist, and the damping is merely based on stress-induced movements of one- and twodimensional defects. In the transition ranges, martensitic and austenite phases coexist, and besides the described phenomena, the applied mechanical stress can additionally lead to stressinduced phase transformation and irreversible energy conver- 

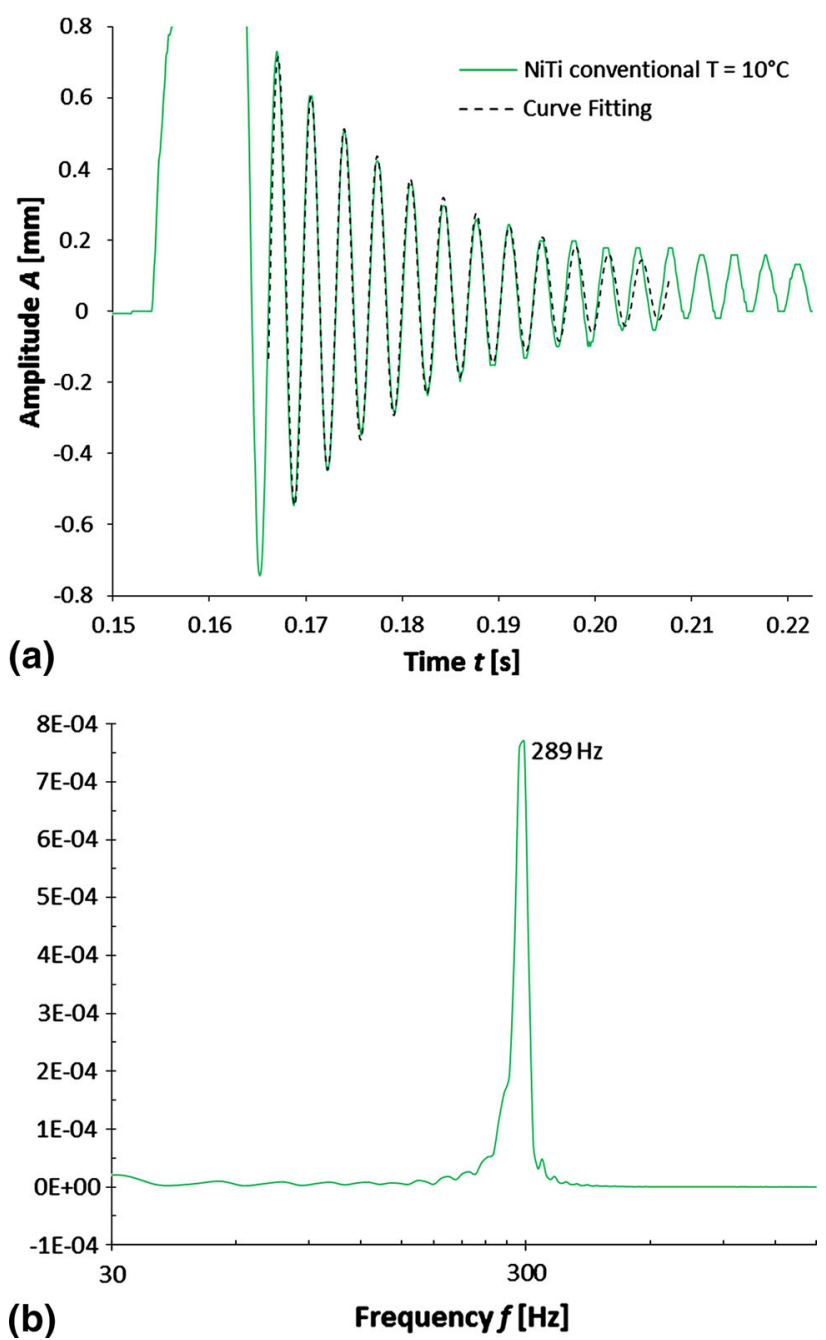

Fig. 3 (a) Trajectory of the damped SLM NiTi cantilever and (b) the related transfer function

sion. Maximal damping values are found at austenite start temperature $A_{\mathrm{s}}$, because the thermally induced lattice transformation becomes available. Here, the critical stress to mechanically induce martensite in thermo-elastically built austenite is minimal according to the Clausius-Clapeyron relation describing martensitic transformations (Ref 21). Furthermore, in this biphasic state, the exothermic stress-induced formation of martensite and the endotherm formation of austenite lead to dissipation of thermal energy (Ref 18). The thermo-elastic contribution has to be considered in particular at higher frequencies, whereas the damping based on defects, twin boundaries and grain boundaries are important at lower frequencies (Ref 18). In our experiments, frequencies of $(300 \pm 50) \mathrm{Hz}$ were found, which are higher than in previous studies, cp. $3 \times 10^{-5}-3 \mathrm{~Hz}(\operatorname{Ref} 22)$ and 0.1-0.4 Hz (Ref 23). To this end, thermo-elastic effects are partially contributing in the damping experiments.

The martensite and austenite damping plateaus at the left and the right of the peak are separated by a temperature difference of about $35 \mathrm{~K}$ in SLM NiTi but only by $20 \mathrm{~K}$ in conventional NiTi. This difference could have its origin in the SLM microstructure and composition modulations. As stated above, due to the laser trajectories and the epitaxial building process (Ref 24), the microstructure of the SLM sample is less homogeneous, highly

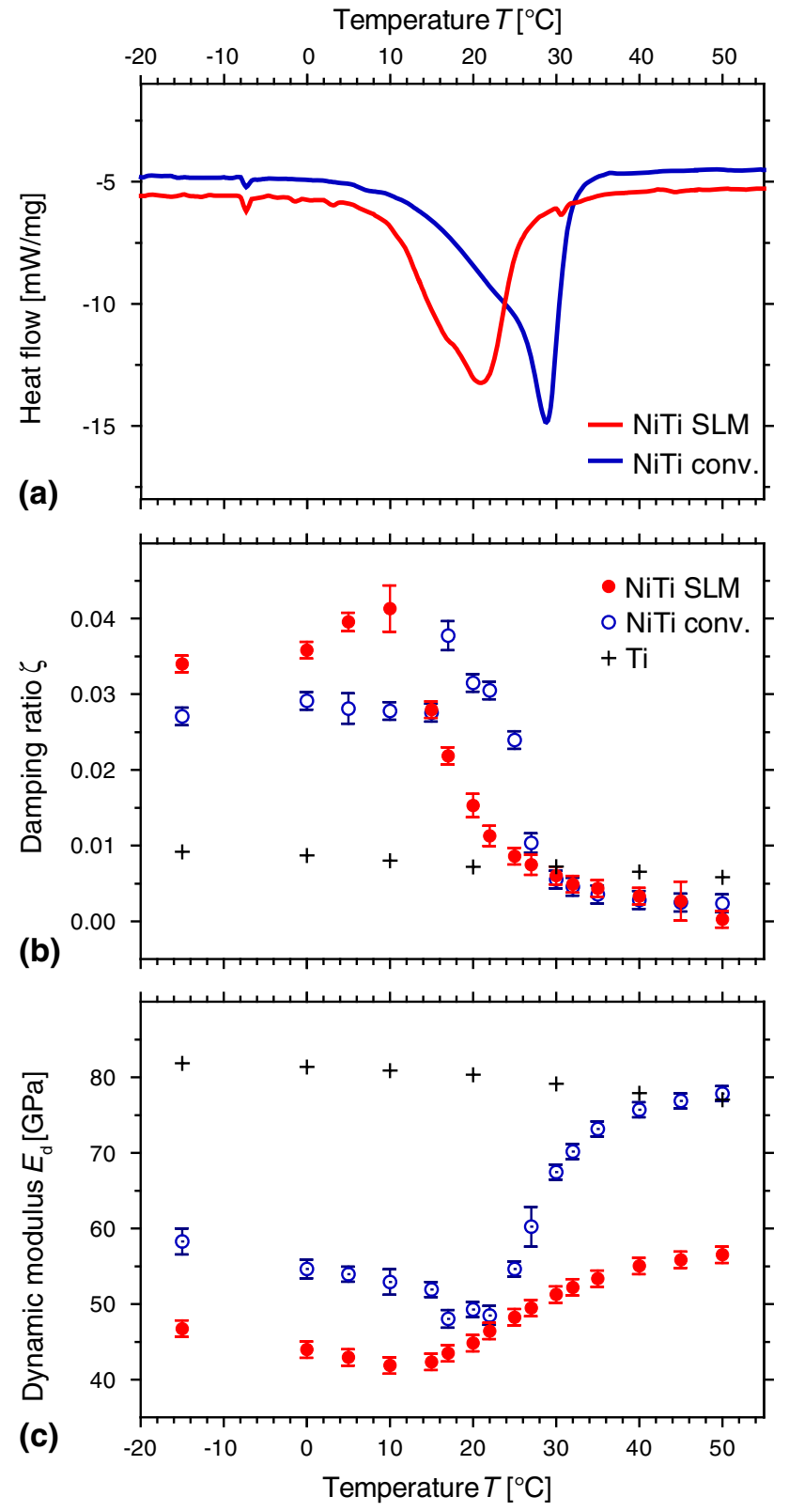

Fig. 4 (a) DSC curves of SLM NiTi (red) and conventional NiTi (blue) during transformation from martensite to austenite. (b) Damping ratio $\zeta$ and (c) dynamic modulus $E_{\mathrm{d}}$ of SLM NiTi $(n=2)$, conventional NiTi $(n=2)$ and titanium $(n=1)$. The error for the temperature corresponds to the width of the symbols (Color figure online)

oriented and shows a broader grain size distribution compared to conventional NiTi. Grain refinement increases the transformation energy and broadens up the DSC peaks (Ref 25), because the transformation is suppressed by crystallographic incompatibility (Ref 26). This effect could explain the broader shape of the transition peak in DSC and the shape of the damping curve of SLM and conventional NiTi, respectively. The method used to determine the damping ratio is suitable for SLM and conventional NiTi, which is reflected by values of the temperaturedependent characteristics and the absolute values that correspond to the data of the literature (Ref 12).

The results of the temperature-dependent static and dynamic elastic moduli are summarized in Table 3. In general, the 


\begin{tabular}{|c|c|c|c|}
\hline & $T=-15^{\circ} \mathrm{C}$ & $\begin{array}{c}T_{\mathrm{SLM} \mathrm{NiTi}}=10^{\circ} \mathrm{C}, \\
T_{\text {conventional NiTi }}=17^{\circ} \mathrm{C}, T_{\mathrm{Ti} \text { reference }}=10^{\circ} \mathrm{C}\end{array}$ & $T=50^{\circ} \mathrm{C}$ \\
\hline$E_{\mathrm{d}}(\mathrm{GPa})$ of conventional $\mathrm{NiTi}$ & $58.3 \pm 1.2(\mathrm{M})$ & $48.0 \pm 0.8(\mathrm{M}$ and $\mathrm{A})$ & $77.8 \pm 0.6(\mathrm{~A})$ \\
\hline$E_{\mathrm{d}}(\mathrm{GPa})$ of $\mathrm{SLM}$ NiTi & $46.7 \pm 0.6(\mathrm{M})$ & $41.9 \pm 0.4(\mathrm{M}$ and $\mathrm{A})$ & $56.5 \pm 0.4(\mathrm{~A})$ \\
\hline$E_{\mathrm{d}}(\mathrm{GPa})$ of Ti reference & 81.9 ( $\alpha$-phase) & 80.9 ( $\alpha$-phase $)$ & 77.0 ( $\alpha$-phase $)$ \\
\hline$E(\mathrm{GPa})$ of conventional NiTi & $22.9 \pm 1.6(\mathrm{M})$ & & $61.3 \pm 4.7(\mathrm{~A})$ \\
\hline$E(\mathrm{GPa})$ of SLM NiTi & $30.0 \pm 4.3(\mathrm{M})$ & & $73.4 \pm 39.1(\mathrm{~A})$ \\
\hline$E_{\text {ref }}(\mathrm{GPa})$ of conventional NiTi & $23-41(\mathrm{M})(\operatorname{Ref} 13)$ & & $70-80(\mathrm{~A})(\operatorname{Ref} 13)$ \\
\hline
\end{tabular}

conventional NiTi is stiffer than the SLM samples. The dynamic elastic modulus $E_{\mathrm{d}}$ of the martensite is smaller compared to the austenitic and is minimal at the temperature of the highest damping ratio $\zeta$, in accordance with previous studies (Ref 27). The smaller dynamic modulus in the martensite phase is attributed to the mobility of interfaces and movement of twin boundaries.

The dynamic elastic moduli derived from the damping experiments are generally higher than the elastic moduli derived from static mechanical testing. For the austenite phase, elastic moduli below 70-80 GPa determined in static mechanical testing are usually attributed to an early stress-induced martensite formation (Ref 28, 29). Early means that austenite is transformed into martensite before the actual plateau region is reached, which contributes to lower slopes in the linear-elastic part of the stress-strain curve. During the cantilever oscillations in the damping experiments, stress-induced martensite formation seems not to be dominant, as this would contribute to an increased damping ratio in the austenite phase in comparison to titanium. Therefore, the dynamic elastic modulus derived from the oscillating cantilevers is higher than the statically determined value. A similar effect might occur for the martensite phase. Here, de-twinning and martensite reorientation in static mechanical testing can occur at low stresses prior to the actual plateau in the stress-strain curves lowering the elastic modulus (Ref 30, 31). During high-frequency oscillations, de-twinning might have been less dominant resulting in a higher elastic modulus. As phase transformation and de-twinning, which contribute to the lower elastic moduli in static mechanical testing, are distinct from actual elasticity, we consider the dynamic moduli derived from the damping experiments closer to the true elastic moduli of the tested NiTi specimens. Comparing the moduli of SLM and conventional NiTi, the lower elastic moduli of the SLM-fabricated parts might be partially caused by residual porosity due to powder-based manufacturing route (Ref 8 ). A maximum residual porosity of $5 \%$, however, cannot explain the actual differences between SLM and conventional NiTi of approximately 20\%. Another reason for the differing elastic moduli is a shift in the atomic composition of the SLM NiTi, as the SLM process is associated with Ni-loss due to evaporation and uptake of oxygen. The dissimilar moduli, therefore, originate most probably from distinct atomic compositions of conventional and SLM NiTi.

\section{Conclusions}

In this study, we compared the damping characteristics of conventionally produced NiTi with NiTi structures produced by selective laser melting. We have shown that their damping ratio $\zeta$ is characteristic for the phases that exist at specific temperature ranges. The results indicate that medical implants from conventional and SLM NiTi can be fabricated and can exhibit ultra-high mechanical damping properties.

\section{Acknowledgments}

The multi-disciplinary team gratefully acknowledges the financial support of the Swiss National Science Foundation within the program NRP 62 "Smart Materials." We sincerely thank MEMRY $\mathrm{GmbH}$ for the supply of the pre-alloyed NiTi powder and the conventional NiTi cantilevers and the inspiring discussions.

\section{References}

1. T. Xing, Y. Zheng, and L. Cui, Transformation and Damping Characteristics of NiTi/NiTi Alloys Synthesized by Explosive Welding, Mater. Trans., 2006, 47(3), p 658-660

2. J. van Humbeeck, Non-medical Applications of Shape Memory Alloys, Mater. Sci. Eng. A: Struct. Mater. Prop. Microstruct. Process., 1999, 273-275, p 134-148

3. T. Bormann, F. Beckmann, M. Schinhammer, H. Deyhle, M. de Wild, and B. Müller, Assessing the Grain Structure of Highly X-ray Absorbing Metallic Alloys, Int. J. Mat. Res., 2013. doi:10.3139/146.111052

4. T. Bormann, R. Schumacher, B. Müller, M. Mertmann, and M. de Wild, Tailoring Selective Laser Melting Process Parameters for NiTi Implants, J. Mater. Eng. Perform., 2012, 21(12), p 2514-2519

5. L.C. Brinson, I. Schmidt, and R. Lammering, Stress-Induced Transformation Behavior of a Polycrystalline NiTi Shape Memory Alloy: Micro and Macromechanical Investigations Via In Situ Optical Microscopy, J. Mech. Phys. Solids, 2004, 52, p 1549-1571

6. T. Bormann, R. Schumacher, B. Müller, M. Mertmann, U. Pieles, and M. de Wild, Properties of NiTi-Structures Fabricated by Selective Laser Melting, eCells Mater. J., 2010, 20(Suppl. 1), p 13

7. H. Meier, C. Haberland, and J. Frenzel, Structural and functional properties of NiTi shape memory alloy produced by selective laser melting, in Innovative Developments in Design and Manufacturing: Advanced Research in Virtual and Rapid Prototyping, CRC PressTaylor \& Francis Group, London, 2012, p 291-296

8. T. Bormann, S. Friess, M. de Wild, R. Schumacher, G. Schulz, and B. Müller, Determination of Strain Fields in Porous Shape Memory Alloys Using Micro Computed Tomography, Proc. SPIE, 2010, 7804, p 78041M

9. T. Bormann, M. de Wild, F. Beckmann, and B. Müller, Assessing the Morphology of Selective Laser Melted NiTi-Scaffolds for a ThreeDimensional Quantification of the One-Way Shape Memory Effect, Proc. SPIE, 2013, 8689, p 868914

10. T. Bormann, R. Schumacher, B. Müller, M. de Wild, Fabrication and characterization of anisotropic NiTi specimens for load-bearing implants, Proceedings of the International Conference on Shape Memory and Superelastic Technologies, May 20-24, 2013, Prague, Czech Republic, 2013, p 147-148

11. H. Kuchling, Taschenbuch der Physik, Verlag Harri Deutsch, Frankfurt am Main, Germany, 1984 
12. H.C. Lin, S.K. Wu, and M.T. Yeh, Damping Characteristics of TiNi Shape Memory Alloys, Metal. Mater. Trans. A, 1993, 24, p 2189-2194

13. Ausgewählte Eigenschaften von NiTi-Legierungen, Accessed on 25 November, 2013, http://www.memory-metalle.de/html/03_knowhow/ PDF/MM 04 properties d.pdf

14. D.E. Hudson, Internal Friction in Metals, Engineering and Applied Science, California Institute of Technology, Pasadena, CA, 1942

15. E.D. Brandnert, B.S. Shivaram, and A. Munier, Design and Fabrication of an Inverted Torsion Pendulum for Internal Friction Measurements, Meas. Sci. Technol., 1995, 6, p 310-313

16. Y. Liu and J. van Humbeeck, On the Damping Behaviour of NiTi Shape Memory Alloy, J. Phys. IV France, Supplément au Journal de Physique III, 7(Colloque C5), 1997, p 519-524

17. M. Kaack, Elastische Eigenschaften von NiTi-Formgedächtnis-Legierungen, Fakultät für Physik und Astronomie, Ruhr-Universität Bochum, Bochum, 2002

18. I. Schmidt, Untersuchung zur Dämpfungskapazität superelastischer Nickel-Titan-Formgedächtnislegierungen, Institut für Mechanik, Helmut Schmidt Universität, Hamburg, 2004

19. I. Schmidt and R. Lammering, Dynamisches Verhalten einer Superelastischen NiTi-Legierung, Technol. Mech., 2000, 20(1), p 51-60

20. J. van Humbeeck, Damping Properties of Shape Memory Alloys During Phase Transformation, J. Phys. IV, Supplément au Journal de Physique III, 6 (Colloque C8), 1996, p 371-380

21. Y. Liu and H. Yang, Strain Dependence of the Clausius-Clapeyron Relation for Thermoelastic Martensitic Transformations in NiTi, Smart Mater. Struct., 2007, 16, p S22-S27

22. H. Soul, A. Isalgue, A. Yawny, V. Torra, and F.C. Lovey, Pseudoelastic Fatigue of NiTi Wires: Frequency and Size Effects on Damping Capacity, Smart Mater. Struct., 2010, 19(8), p 085006
23. H. Yin and Q. Sun, Temperature Variation in NiTi Shape Memory Alloy During Cyclic Phase Transition, J. Mater. Eng. Perform., 2012, 21(12), p 2505-2508

24. T. Bormann, R. Schumacher, B. Müller and M. de Wild, From Powder to Complex-Shaped NiTi Structures by Selective Laser Melting, Euro PM2012 Proceedings, 1, 2012, p 193-197

25. T. Waitz, W. Pranger, T. Antretter, F.D. Fischer, and H.P. Karnthaler, Competing Accommodation Mechanisms of the Martensite in Nanocrystalline NiTi Shape Memory Alloys, Mater. Sci. Eng. A: Struct. Mater. Prop. Microstruct. Process., 2008, 481-482, p 479483

26. J. Frenzel, E.P. George, A. Dlouhy, C. Somsen, M.F.-X. Wagner, and G. Eggeler, Influence of $\mathrm{Ni}$ on Martensitic Phase Transformations in NiTi Shape Memory Alloys, Acta Mater, 2010, 58, p 3444-3458

27. K.N. Melton and O. Mercier, The Mechanical Properties of NiTi-Based Shape Memory Alloys, Acta Metal., 1981, 29(2), p 393-398

28. Y. Liu and H. Xiang, Apparent Modulus of Elasticity of NearEquiatomic NiTi, J. Alloys Compd., 1998, 270, p 154-159

29. P. Sittner, L. Heller, J. Pilch, C. Curfs, T. Alonso and D. Favier, Young's Modulus of Austenite and Martensite Phases in Superelastic NiTi Wires, Proceedings of the International Conference on Shape Memory and Superelastic Technologies, May 20-24, 2013, Prague, Czech Republic., 2013, p 37-38

30. S. Rajagopalan, A.L. Little, M.A.M. Bourke, and R. Vaidyanathan, Elastic Modulus of Shape-Memory NiTi from In Situ Neutron Diffraction During Macroscopic Loading, Instrumented Indentation, And Extensometry, Appl. Phys. Lett., 2005, 86, p 081901

31. S. Qiu, B. Clausen, S.A. Padula, R.D. Noebe, and R. Vaidyanathan, On Elastic Moduli and Elastic Anisotropy in Polycrystalline Martensitic NiTi, Acta Mater., 2011, 59, p 5055-5066 